\title{
WORKING CAPACITY AFTER THYROIDECTOMY
}

BY

\author{
W. L. SCOTT and J. W. PARKS
}

From the Medical Department, General Post Office, London

Since the introduction of improved methods of surgical treatment of thyroid disturbance-largely the result, in this country, of team work by Dunhill, Joll, Keynes, and others-the risk has been considerably lessened. Joll (1932) reported over 85 per cent. of cures, and Linnell and Keynes (1939) have stated that the great majority of patients can resume approximately normal lives.

In order to assess the working capacity of patients who have undergone thyroidectomy, 105 cases occurring amongst Post Office workers have been analysed over a period of fifteen years. The results were worked out from accurately kept sick records and not from after-histories based on the statements of individual patients which often tend to be unreliable. Although all the cases were of proved thyrotoxicosis it was impossible to separate those of primary exophthalmic goitre from others of secondary adenomatous goitre; nor was it possible to obtain information regarding the preoperative condition, the presence or absence of complications, or the technique employed-all of which have an important bearing on the end result.

The sample consists of 38 men and 67 women. The latter were employed on sedentary work as clerical officers, telephonists, counter clerks or telegraphists, whilst seven of the men were engaged on similar duties, and the remainder on manual work as postmen, sorters or engineering workmen.

\section{Age distribution}

Table I shows the age distribution at the time of operation. It will be seen that the largest number

TABLE 1

\begin{tabular}{l|r|r|r}
\hline & \multicolumn{3}{|c}{ Numbers } \\
Age group & \multicolumn{3}{|c}{} \\
\cline { 2 - 4 } & Men & Women & Total \\
\hline $19-25$ & 5 & 12 & 17 \\
$25-30$ & 2 & 10 & 12 \\
$30-35$ & 2 & 14 & 16 \\
$35-40$ & 10 & 14 & 24 \\
$40-45$ & 10 & 5 & 15 \\
$45-50$ & 6 & 7 & 13 \\
$50-55$ & 2 & 5 & 7 \\
$55-60$ & 1 & 0 & 105 \\
\hline Totals & 38 & 67 & \\
\hline
\end{tabular}

of cases occurred in the age group 35-40 and the smallest in the 55-60 group, a steep fall taking place after the age of 50 .

\section{Analysis}

The cases have been analysed into two groupsthose who died or retired on medical grounds, and those who are still in the service or have retired for non-medical reasons (see Table 2).

Post-operative deaths occurred in four casestwo men and two women, one of whom had valvular disease of the heart. These deaths took place in the years 1935 and 1938 in which fifty cases underwent operation, a mortality figure of 8 per cent., which compares unfavourably with the findings of Heyd (1942) who, dealing with similar numbers108 cases between the years 1934 and 1939-reported no deaths although in his series of 106 cases between 1929 and 1934 the mortality was 6.5 per cent. Other observers in this country have reported varying mortality rates, Morley (1936) 3.7 per cent.; Linnell and Keynes (1939) 1.1 per cent.; Dobson, Seely and Rose (1942) 1.5 per cent.; but the total number of cases observed was never less than 300 .

Seven of our cases failed to return to work after operation; one had thyroidectomy in 1931 and the remaining six between the years 1934 and 1939.

Ninety-four cases resumed duty after operation, but of these, thirteen, ten of whom were women, were later invalided on medical grounds after an average service of 3.2 years. Symptoms of thyrotoxicosis recurred in four cases and led to retirement, whilst two were invalided on account of melancholia, and two because of functional nervous disorders. Rheumatoid arthritis, chronic iliac strain, toxic choroiditis, chronic pelvic inflammation following hysterectomy, and hyperpiesia accounted for the remainder. Thus medical causes accounted for the loss of 20.9 per cent. of the sample within five years of the operation. Of those women who did not return to duty, or returned to duty and were subsequently invalided on medical grounds,' 47 per cent., or nearly half, were over 40 years of age at the time of operation. The post-operative prognosis in women over 40 must be considered poor. It may be that the menopause has a more serious effect because of the unbalanced endocrine system due to thyrotoxicosis. The yearly average pre-operation ick rate of those invalided was $\mathbf{5 8}$ days and compared 
WORKING CAPACITY AFTER THYROIDECTOMY

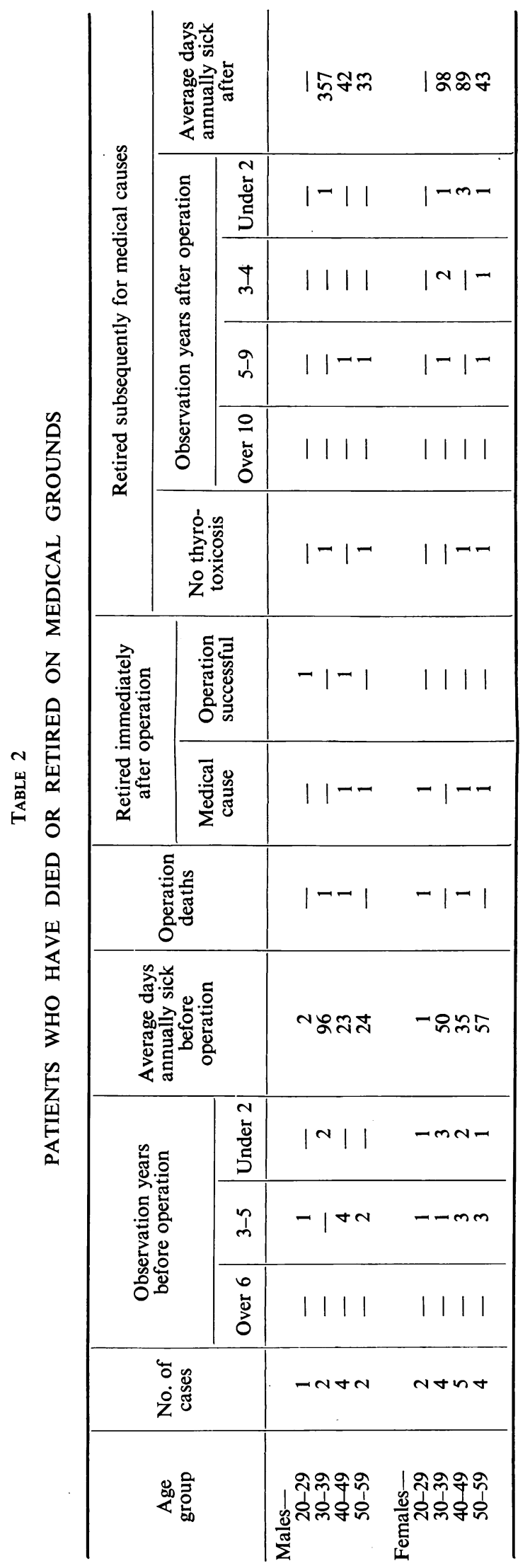

\begin{tabular}{|c|c|c|c|}
\hline \multicolumn{2}{|c|}{ 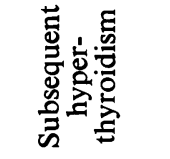 } & -111 & $-N-1$ \\
\hline \multicolumn{2}{|c|}{ 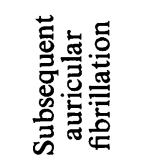 } & $1-N-$ & 1111 \\
\hline \multicolumn{2}{|c|}{ 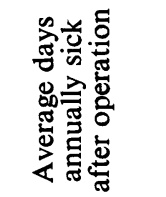 } & $=\infty \pm$ & $\simeq=m m$ \\
\hline \multirow{4}{*}{ 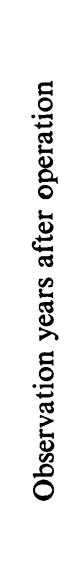 } & 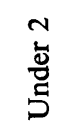 & 1111 & $+1-1$ \\
\hline & I & $N-1 \mid$ & $m-11$ \\
\hline & ì & NINN & エ90- \\
\hline & $\begin{array}{l}\text { 음 } \\
\text { ờ }\end{array}$ & $N-||$ & Nm | | \\
\hline \multicolumn{2}{|c|}{ 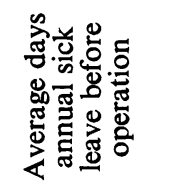 } & 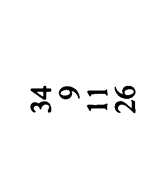 & రిగ뉴లి \\
\hline \multirow{3}{*}{ 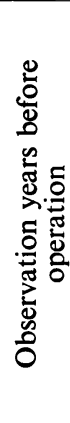 } & $\begin{array}{l}N \\
\stackrel{5}{0} \\
5 \\
5\end{array}$ & $\operatorname{\theta nn} \mid$ & $=0 \mathrm{~m} \mid$ \\
\hline & $n$ & Ntan & rmm- \\
\hline & $\begin{array}{l}0 \\
\stackrel{0}{0} \\
0\end{array}$ & $11-1$ & $m \mid-1$ \\
\hline \multicolumn{2}{|c|}{ 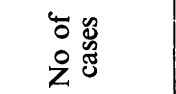 } & bagn & สฆกーー \\
\hline \multicolumn{2}{|c|}{ 品高 } & 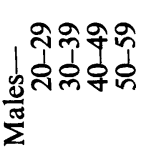 & 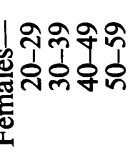 \\
\hline
\end{tabular}

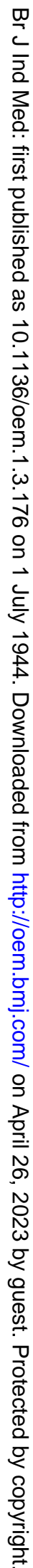


with 17 days for 55 of the remaining 68 cases who are still in the service. (As a result of war conditions it was not possible to obtain preoperation sick records in 13 cases.) It seems that the wear and tear on the vascular and nervous systems in these cases is sufficiently serious to influence the results of thyroidectomy, and it is clear that the earlier operative measures are carried out the better.

Of the remaining cases, thirteen women resigned, eight for marriage, three to take up other work, and one to join H.M. Forces. Three of the 68 still in the service have auricular fibrillation, two have had a second thyroidectomy, one has developed pulmonary tuberculosis, and one cerebral arteriosclerosis. These cases have been under observation for from five to fifteen years following thyroidectomy. In this group it was found that recovery from operation took from five to six months, but after resumption of duty the yearly average sick rate amounted to 9.1 days for men and 9.4 for women-an average of 9.3 days per year, which is remarkably low particularly as the years of observation covered the war period.

Scrutiny of the causes of sick absence failed to reveal any salient features. In ten cases tonsillitis and sinusitis accounted for most of the absence, and Heyd (1942) stressed the importance of the part played by infections of the nose and throat in lighting up nervous or cardiac symptoms in these cases. Recurrence of symptoms of thyrotoxicosis causing temporary incapacity took place in 7.4 per cent. of the group of 81 cases, but the absences were of short duration in four of these.

An attempt was made to assess the improvement in operative methods in terms of sick absence, but the group was too small to be of any value. A total of eleven cases operated on before 1935 had an average annual sick rate of only 6.8 days, but at that time thyroidectomy was less common than it is to-day and only the less severe cases were so treated.

\section{Conclusions}

Our experience goes to show that, in the $79 \cdot 1$ per cent. of cases of thyroidectomy in which death or retirement did not take place, the level of subsequent health and working capacity was not inferior to that of normal individuals. The earlier the operation the better the prospects of a complete recovery.

Where prospects have to be assessed in relation to acceptance for a pension or superannuation scheme, a preliminary period of observation of at least three years after operation is advisable.

\section{Summary}

1. 105 cases of thyroidectomy in Post Office workers between the years 1929 and 1943 have been analysed; of these 4 died, 7 did not return to work, 13 resigned, and 13 were invalided on medical grounds.

2. Medical causes accounted for the death or retirement of 20.9 per cent. of the sample during the five years following operation.

3. Of women retired, 47 per cent. were over 40 at the time of operation.

4. Pre-operation sick rates were higher amongst those subsequently retired than the rates incurred by patients still in the service.

5. The average length of post-thyroidectomy service of subjects subsequently retired on medical grounds was $3 \cdot 2$ years.

6. The average annual sick rate of those remaining in the service has been $9 \cdot 3$ days per year, $9 \cdot 1$ days for men and 9.4 days for women.

We should like to express our thanks to Mr. A. E. Green of the Medical Department, General Post Office, for his assistance in the recording of these cases.

\section{REFERENCES}

Dobson, L., Seely, H., and Rose, H. J. (1942). Ann. Surg., 115, 199.

Heyd, C. G. (1942). Amer. J. Surg., 55, 18.

Joll, C. A. (1932). Diseases of the Thyroid Gland, Heinemann, London, p. 611.

Linnell, J. W., and Keynes, G. (1939). Brit. med. J., 1, 764.

Morley, J. (1936). Ibid., 1, 827. 